\title{
Poe: uma história de traduções, inspirações e popularidade
}

\section{Poe: a history of translations, inspirations, and popularity}

\author{
Francisco Francimar de Sousa Alves
}

Resumo: Este artigo traz um panorama geral da recepção de Edgar Allan Poe em muitos países, procurando mostrar a importância da sua obra para a literatura universal, desde a primeira tradução de um dos seus contos publicada no continente europeu. Ainda procura-se destacar a reputação, a fama e a popularidade do autor que inspiraria renomados escritores em quase todo o mundo, o que vem justificar o seu interesse em traduzir contos e poemas do mestre da literatura fantástica.

Palavras-chave: Poe, tradução, recepção, popularidade.

Abstract: This article gives a general view of the reception of Edgar Allan Poe in many countries, as it tries to show the importance of his works for worldwide literature since the first translation of one of his short stories published in Europe. This paper also tries to emphasize the reputation, fame, and popularity of the author who would inspire renowned writers almost everywhere, a fact which comes to justify their interest in translating tales and poems of the master of fantastic literature.

Keywords: Poe, translation, reception, popularity.

\footnotetext{
Professor da Universidade Federal de Campina Grande - Campus de Cajazeiras-PB. Doutor em Estudos da Tradução (UFSC). E-mail: ff.alv@bol.com.br
} 
ALVES, F. F. DE S. - Poe: uma história de traduções, inspirações e popularidade

O contista, poeta, ensaísta e crítico literário Edgar Allan Poe (18091849) teve um percurso de vida conturbado, desregrado e aventureiro, "uma vida corrida, atribulada e cheia de contínuos acontecimentos extraordinários, derivados do seu gênio criativo e temperamental" (ARAúJo 2002: 17), mas apesar de seus desatinos, deixou um legado de grandes obras, como poemas românticos, histórias de horror e mistério, sátiras, contos policiais e ensaios críticos-filosóficos. Considerado um dos mais importantes escritores da literatura universal, e ainda um dos precursores da literatura de ficção científica e fantástica modernas, Poe contribuiu para o enriquecimento de vários sistemas literários em quase todo o mundo.

Decerto Poe é dono de uma criatividade ímpar, mas o que levou sua fama ao mundo foi, antes de tudo, o reconhecimento do poeta francês, Baudelaire, que logo percebeu o potencial literário do escritor norteamericano. A exemplo de Baudelaire, Poe conseguiu atrair a admiração de outros renomados simbolistas franceses, como Mallarmé e Valéry. Enquanto Baudelaire traduzia os contos de Poe, Mallarmé se dedicava à poesia, inclusive "um dos seus poemas ["Le Tombeau d'Edgar Poe"] mostra como Mallarmé foi inspirado pelo poeta americano” (Rosselet 1941: 7). ${ }^{1}$

Para Valéry, nas palavras de Todorov (1980: 156), "Poe encarnava com perfeição a tendência que consiste em dominar o processo de criação, em reduzi-lo a um jogo de regras". Certamente os simbolistas franceses reconheceram Poe como mestre, todavia, foi Baudelaire o responsável pela divulgação da sua obra, pois foi a partir deste que o mundo veio a conhecer o talento do contista americano. Entre os vários elogios baudelairianos ao fazer literário de Poe, um deles merece destaque:

Seu estilo é puro, adequado às ideias, dando delas a expressão exata. Poe é sempre correto. (...) Como poeta, Edgar Poe é um

\footnotetext{
1 “one of his own poems ['Le Tombeau d'Edgar Poe'] shows how strongly he had come under the spell of the American poet"
} 
ALVES, F. F. DE S. - Poe: uma história de traduções, inspirações e popularidade

homem à parte. Representa quase sozinho o movimento romântico do outro lado do Oceano. É o primeiro americano que, propriamente falando, fez do seu estilo uma ferramenta. Sua poesia, profunda e gemente, é, não obstante, trabalhada, pura, correta e brilhante, como uma joia de cristal. (...) Nenhum homem jamais contou com maior magia as exceções da vida humana e da natureza. ${ }^{2}$

Em 1845, quando ainda não era chegado o momento de glória para o poeta no continente europeu, "a revista francesa La Revue Britannique era a primeira a publicar na Europa uma tradução de um dos contos de Poe ["O escaravelho de ouro”]” (D’AMELIO 2010: 103). ${ }^{3}$ Entretanto, em 1848, tem início a projeção de Poe na França, quando Baudelaire publica no periódico La Liberté de Penser, "Révelation Magnétique” ["Revelação Mesmeriana”], sua primeira tradução do mestre do conto fantástico. Entre 1848 e 1855 o escritor francês publica algumas traduções de Poe em jornais, por exemplo, o Le Pays. Contudo, foi a partir da publicação do primeiro volume de traduções de treze contos com o título de Histoires Extraordinaires (1856), dos originais de Poe em Tales of the Grotesque and Arabesque (25 contos), escritos entre $1832 \mathrm{e}$ 1845, que o escritor estadunidense teve sua obra disseminada no cenário literário ocidental (França, Europa, América Latina). Nos dois anos seguintes, - escritor francês publica Nouvelles Histoires Extraordinaires (1857) e Aventures de Gordon Pym (1858). Em 1863, publica Eureka; em 1865, Histoires Grotesques et Sérieuses. Logo, "foi através da tradução de Baudelaire que o mundo literário ocidental tomou conhecimento da novidade e do valor da mensagem do autor norte-americano" (MENDES 2001: 53), um "padrinho" francês que reconheceu o verdadeiro talento do seu "protegido" antes mesmo do seu próprio país, uma vez que, até então, sua obra se encontrava um tanto “periférica” nos Estados Unidos, sendo “considerado um

\footnotetext{
2 BAUDELAIRE, C. "O homem e a obra". Disponível em: http://allanpoe4.blogspot.com.br. Acesso em: 19 set. 2012.

3 "the French magazine La Revue Britannique was the first in Europe to publish a translation of one of Poe's tales ['The Gold Bug']”.
} 
ALVES, F. F. DE S. - Poe: uma história de traduções, inspirações e popularidade

escritor de segunda categoria, seguidor do movimento romântico: um sucessor dos chamados 'romancistas góticos', na prosa, e um imitador de Byron e Shelley, nos versos" (SANTAELLA 1987: 146). É interessante observar que Poe ainda teve a oportunidade de experimentar esse reconhecimento em vida, pois, nas palavras de Rónai (1987: 106), "no momento em que Baudelaire the descobriu a obra, Poe era considerado pelos contemporâneos como importante crítico, mas os seus poemas e contos eram pouco apreciados".

No que concerne à divulgação da obra de um escritor estrangeiro através de traduções, que é o caso especial da empatia de Baudelaire em relação a Poe, Lentz (2008: 2) observa que, "o projeto de tradução das obras de Edgar Allan Poe ao francês por Baudelaire talvez figure como um dos mais famosos e sucedidos êxitos literários de divulgação da obra de um escritor, em língua de chegada". Lentz acredita que isso "parece pertencer mais a uma história da tradução do que mesmo àquela literária, da qual faz parte" (ibidem). É importante salientar que, várias das traduções de Poe que chegaram a alguns países [inclusive ao Brasil], não partiram do original em inglês, e sim da tradução francesa (MOREIRA 2009: 217).

Poe não apenas inspirou grandes simbolistas franceses, mas igualmente escritores latinos, chegando a ser considerado o pai do movimento simbolista. As palavras de Santaella apontam a grande importância do autor norteamericano para a França e América Latina:

E. A. Poe foi, antes de tudo, uma constelação lançando diferenciados raios para o futuro. Em vista disso, podemos afirmar sem embaraços que, se a influência de Poe no século XIX estava na França, no século XX seu espírito emigrou para a América Latina. Os franceses receberam da teoria e prática poeanas as primeiras lições sobre o poder de sugestão do indefinido como elemento, da verdadeira poiesis, isto é, a construção precisa do impreciso, que os poetas simbolistas levariam, na França, às últimas conseqüências. Já na América Latina deste nosso século, por outro lado, é impossível pensar o boom da prosa ficcional dita "fantástica" sem pensar em E. A. Poe (SANTAELLA 1987: 150-151). 
ALVES, F. F. DE S. - Poe: uma história de traduções, inspirações e popularidade

Além de Baudelaire, Mallarmé e Valéry, outros proeminentes escritores franceses também foram atraídos pela literatura poeana, como é o caso de Emile Gaboriau, primeiro discípulo de Poe no gênero do romance policial; Júlio Verne, na linha do romance de ficção científica e de aventuras fantásticas; Maupassant [no conto fantástico], J. H. Rosny, no campo do romance científico; Théophile Gautier e outros (MENDES 2001: 53-54). Contudo, Villiers de l'Isle Adam "se mostrou um discípulo fiel que muitas vezes superou o mestre. Sua paixão e admiração por Poe levaram-no a decorar deste contos inteiros, que declamava com emoção impressionante" (ibidem: 54). Poe também repercutiu no gênero dramático francês na ópera Pelléas et Mélisande. Conforme Rosselet (1941: 9), "Pelleas e Melisande, como Roderick Usher, ficam apavorados pelo medo, medo do Destino e da Morte". ${ }^{4}$

No mesmo ano em que a obra de Poe começa a se destacar na França, ela entra no sistema literário russo, um ano antes da morte do poeta. Assim, em 1848, Poe já era conhecido do público russo como um escritor de contos e nas décadas de 1850 e 1860 sua popularidade aumentou por ocasião dos ensaios de Baudelaire (D'AMELIO 2010: 103-104). O poeta Constantino Balmont caracterizou-se pelas notáveis traduções e adaptações das poesias de Poe e a primeira tradução de "O Corvo" pelo poeta S. A. Andreievski surgia no Mensageiro da Europa no ano de 1878. Em pleno regime soviético o poeta Briusov publica Edgar Poe - Coleção Completa de Poemas e Versos; outrossim, a obra de Dostoiévski foi profundamente marcada por Edgar Poe (MENDEs 2001: 55-56), que também escreveu um prefácio à tradução de três contos do autor, intitulado "Trois récits d'Edgar Poe" onde tecia elogios ao processo criativo, à imaginação e ao talento de Poe (FIGUEIREDo 2009: 67). Portanto, podemos perceber o prestígio do estadunidense naquele país, uma vez que a sua carga cultural "levou escritores russos a sérias considerações e a um elevado nível de traduções. As traduções de Balmont e Briusov têm significação especial e

\footnotetext{
4 "Pelleas and Melisande, like Roderick Usher, are haunted by fear, fear of Destiny, fear of Death."
} 
ALVES, F. F. DE S. - Poe: uma história de traduções, inspirações e popularidade

ilustram pontos de vista quase antagônicos quanto ao papel do tradutor" (D'AMELIO 2010: 104). ${ }^{5}$

No que diz respeito a "O Corvo", convém observar que este poema, possivelmente o mais famoso do mundo, se encontra entre "os mais traduzidos poemas curtos da história da literatura. Encontram-se traduções dele em todas as línguas, das neolatinas (...) às eslavas, passando pelas nórdicas, insuladas (como o basco) e artificiais (o esperanto)" (ABRAMo 1999: $64)$.

Além da Rússia, vários países europeus (Espanha, Itália, Alemanha, Inglaterra, Portugal) e latino-americanos (Colômbia, Uruguai, Argentina, Brasil) também publicaram traduções e adaptações de contos de Poe a partir da versão de Baudelaire.

$\mathrm{Na}$ Espanha surgiram muitas traduções de contos de Poe, tendo a sua maioria a versão francesa de Baudelaire [Histoires Extraordinaires] como fonte imediata. A primeira delas foi em 1857, uma adaptação anônima de um conto do escritor (FIGUEIREDo 2009: 67-68). Mas só em 1869, a América espanhola recebe a primeira tradução de Poe, sendo então sua obra difundida nessa região a partir da Espanha. Neste país, o Poe contista teve mais repercussão do que o Poe poeta, ao contrário do que aconteceu na América espanhola, território onde sua poesia foi mais intensa (SALINAS 1941: 23-24). ${ }^{6} \mathrm{O}$ nicaraguense Rubén Darío, renomado poeta lírico de língua espanhola, foi um grande admirador de Poe. Em seu poema "Los raros" "dedicou a Poe um

\footnotetext{
5 "the cult of Poe led Russian artists to serious considerations and a high level of translations. Balmont and Briusov's translations are of particular significance and illustrate almost antinomic views on the translator's role."

6 “ (...) in Spanish America there were no translations of Poe until the year 1869. (...) Edgar Allan Poe, and their diffusion [of the short stories] throughout the Spanish speaking world belongs to Spain. (...) If Spain was the discoverer of Poe the prose writer, it was Spanish America that discovered Poe the poet."
} 
ALVES, F. F. DE S. - Poe: uma história de traduções, inspirações e popularidade

estudo repleto de solidariedade e inteligência; e em muitos dos seus poemas podemos observar a marca do espírito poeano" (ibidem: 25$){ }^{7}$

Em diferentes países da América espanhola encontramos outros grandes nomes da literatura que traduziram obras de Poe ou se inspiraram no mesmo. Nos poemas de Amado Nervo, poeta popular mexicano do século XX, encontramos tendências misteriosas e trágicas do autor de "The Raven"; José Asunción Silva (poeta colombiano) foi um grande admirador de Poe, que buscou imitar na língua espanhola inovações do poeta norte-americano; no Uruguai, as teorias de beleza poética e de valorização do mistério e do indefinido de Julio Herrera y Reissig foram inspiradas em Poe; e o argentino Leopoldo Lugones, o mais versátil e prolífico poeta modernista, também revelou-se discípulo do mestre da literatura gótica (ibidem: 25$).{ }^{8}$ Assim, "os poetas da América Espanhola, que estavam buscando revolucionar sua linguagem poética, viram em Poe o grande representante do poeta revolucionário, de um inovador", uma referência para o seu movimento de transformação (ibidem: 28). ${ }^{9}$ Conforme Gonçalves (2006: 89), "na América Latina temos os maiores exemplos de seguidores de Poe em Jorge Luis Borges e Júlio Cortázar, ambos leitores aficionados e também tradutores de Poe". Logo, observamos que o escritor americano também foi importante para o mercado literário hispânico, chegando a fascinar muitos e grandes nomes da

\footnotetext{
7 "devoted to Poe a study full of sympathy and intelligence; and in many of his poems we see the trace of Poe's spirit."

8 “(...) in [Amado Nervo's] poems we perceive the mysterious and tragic currents of the author of The Raven. Colombia had a poet, José Asunción Silva (...) was a fervent lover of Poe's poetry, and aspired to imitate in the Spanish language those innovations which the American poet brought to the English poetical language. (...) in Montevideo, (...) [Julio Herrera y Reissig's] theories of poetic beauty, of the value of mystery and indefiniteness come directly from Poe. (...) In the Republic of Argentina, Leopoldo Lugones, the most versatile and prolific of modern poets, reflects in some of his periods and productions the strong pressure that has been exercised on his poetic mind by the North American."

9 "the poets of Spanish America who were attempting a like revolution in Spanish poetic language, saw in Edgar Allan Poe the great figure of a revolutionary poet, of an innovator (...) for their revolution."
} 
ALVES, F. F. DE S. - Poe: uma história de traduções, inspirações e popularidade

poesia em diversos países do território de língua espanhola, como é o caso da Colômbia, Costa Rica, Argentina, e do Equador, México, Chile e Uruguai.

Devido a sua notabilidade, Poe foi considerado o poeta revolucionário de toda uma geração de poetas, com a sua forma ímpar de manipular palavras, sons, ritmos e tons da linguagem poética. Na verdade, Poe foi o ídolo, o líder dos grandes escritores de língua hispânica, fascinando-os e inspirando-os para uma nova literatura.

No caso da Itália, afirma Figueiredo (2009: 67), a primeira tradução (anônima) de Poe foi a coletânea de contos intitulada Storie Orribili (1858) e a primeira tradução de "The Raven", atribuída a S. Salvotti, surgiu em 1881. Segundo Bacigalupo (1999: 62), a primeira notável coletânea de contos de Poe publicada na Itália tem 20 estórias traduzidas por Baccio Emanuele Manieri e traz o título de Storie incredibili. A publicação que é de 1869 traz ainda uma introdução na qual faz referência à tradução de Baudelaire como textofonte. ${ }^{10}$ No que concerne à influência de Poe naquele país, Bacigalupo cita duas renomadas figuras da virada do século XX que se inspiraram no contista: Giovani Pascoli, que escreveu uma breve imitação de quatro versos de "The Raven”, provavelmente em 1876, e Gabriele D’Annunzio, cujos romances II piacere (1889) e L'innocente (1892) têm interiores exuberantes e protagonistas semelhantes àqueles de "A queda da casa de Usher" (ibidem: 64). ${ }^{11}$

Quanto à Alemanha, Poe também teve seus seguidores em Hans Heinz Ewers e Gustav Meyrink, importantes representantes do conto de terror, gênero que já era tradição entre escritores românticos como Hoffmann e

\footnotetext{
10 "The first substantial collection (twelve stories) was Storie incredibili (1869), translated by Baccio Emanuele Manieri, who added an introductory essay citing Baudelaire's translation, from which he worked."

11 "Two of the best-known poets at the turn of the twentieth century have important affiliations with Poe. Giovanni Pascoli (...) did a brief imitation of "The Raven", probably in 1876 (four verses). (...) The other major figure of this period [is] Gabriele D'Annunzio. (...) His novels Il piacere [The Child of Pleasure] (1889) and L'innocente [The Intruder] (1892) have lush interiors and Usher-like protagonists."
} 
ALVES, F. F. DE S. - Poe: uma história de traduções, inspirações e popularidade

Tieck, abrindo assim o caminho para a popularidade do escritor americano (MENDEs 2001: 55). Um exemplo claro da popularidade de Poe na Alemanha, conforme Forclaz (1999: 38), é que "ele é o único escritor americano inserido numa coletânea de clássicos lançada para o grande público alemão". ${ }^{12}$ Forclaz também informa que o primeiro livro de contos de Poe na língua alemã foi publicado em 1853; contudo, a apresentação do escritor ao leitor alemão deve-se ao romancista e contista Friedrich Spielhagen, que, em 1859-1860, publicou em sua antologia alguns poemas do autor americano e escreveu um artigo sobre o mesmo (ibidem: 38-39).

$\mathrm{Na}$ Inglaterra, a fama do americano eclodiu em 1845 com a publicação de "The Raven". Depois de um período de baixa popularidade, o sucesso de Poe só foi recuperado em 1874, quando John Ingram publica as obras completas do contista juntamente com a sua biografia. Swinburne e Oscar Wilde também o reconheceram como mestre (MENDES 2001: 55).

Em Portugal, as primeiras traduções das obras de Poe surgem sob a forma de folhetim em jornais da época. A primeira delas foi "Uma viagem à lua num balão feita pelo holandês Hans Pfaal" publicada no jornal A Opinião (1857), seguida de "Colóquio entre Eiros e Charmion" no Diário de Lisboa (1858), e de "A Entrevista" no Século XIX, em 1864 (FIGUEIREDo 2009: 68). De 1857 a 1910, os contos de Poe passam a fazer parte dos jornais diários e periódicos (sob a forma de folhetim) daquele país, quase todos os anos. Contudo, a partir de 1910 a publicação de seus contos desaparece dos jornais, porque, gradualmente, o folhetim deixa de ser o "carro-chefe" da literatura, abrindo mais espaço para as antologias e volumes coletivos, que já começavam a aparecer em 1876 e que tinham por título um ou outro conto de Poe (ibidem: 70-71). Acredita-se que o primeiro livro com traduções de Poe tenha surgido (anonimamente) em 1886. Só em 1890 é publicado o primeiro

\footnotetext{
12 "An example of Poe's German popularity is the fact that he is the only American writer included in a collection of world classics published in 1980 for the general reader of German."
} 
ALVES, F. F. DE S. - Poe: uma história de traduções, inspirações e popularidade

livro de contos do autor, cuja tradução é atribuída a D. Mencia Mousinho de Albuquerque (ibidem: 72).

Com base em levantamento feito por Figueiredo (2009: 71), os dez contos mais vezes traduzidos ou reeditados em Portugal são: "O poço e o pêndulo" e "O gato preto" (28 vezes); "O escaravelho de ouro" (27 vezes); "Os crimes da Rua Morgue" (23 vezes); "O barril de Amontillado" (22 vezes); "Berenice" (21 vezes); "O coração revelador" (20 vezes); "A carta roubada" (19 vezes); e "Hop-Frog" e "William Wilson" (18 vezes). Levando-se em consideração esses números, temos um total de 224 publicações dos contos mais lidos. ${ }^{13}$ Além de D. Mencia Albuquerque, outros portugueses que mais traduziram contos de Poe estão os nomes de João Costa, José Couto Nogueira, Luísa Feijó, Manuel Barbosa e Teixeira de Aguilar. Convém observar que escritores portugueses de renome também traduziram obras de Poe: Antero de Quental, por exemplo, traduziu o conto “A Entrevista" ["The Assignation”] e Fernando Pessoa traduziu três poemas ("O Corvo", "Annabel Lee" e "Ulalume") e escreveu alguns contos de raciocínio ("O Banqueiro Anarquista", “A Carta Mágica” e “A Arte de Raciocinar”) (ibidem: 93-94).

A arte criativa de Poe inspirou, como em outros países, renomados escritores brasileiros: Machado de Assis, Monteiro Lobato, Álvares de Azevedo, Hugo de Carvalho Ramos, o poeta Cruz e Souza entre outros. Em Quincas Borba, de Machado de Assis, podemos encontrar traços de "The Man of the Crowd" e "The Raven". Outra semelhança é entre "The System of Doctor Tarr and Professor Feather" e "O Alienista", visto que ambas as histórias falam de médicos especializados em problemas mentais e tratam de temas como, “loucura, ambiguidade e inversão". Poe e Machado também fazem uso da sátira, do humor, portanto, há grandes marcas de Poe na obra de Machado (DAGHLIAN 1999: 131). Vale ressaltar que a primeira tradução brasileira de "The Raven" foi a de Machado, em 1883. Encontramos também o espírito

\footnotetext{
${ }^{13}$ Considero aqui os dados coletados até o primeiro semestre de 2009, uma vez que o artigo foi publicado no segundo semestre do mesmo ano.
} 
ALVES, F. F. DE S. - Poe: uma história de traduções, inspirações e popularidade

poeano em alguns contos de Lobato; a figura da mulher idealizada na poesia de Álvares de Azevedo; em Carvalho Ramos, contos que refletem suas leituras de Poe e Hoffmann; e ainda Cruz e Sousa, maior simbolista brasileiro, teve em Poe um grande antecessor. Os contos de Hugo de Carvalho Ramos refletem suas leituras de Hoffmann e Poe através do clima psicológico e de sua realização estilística (ibidem: 132).

A importância e influência literária de Poe são, indubitavelmente, indicadores do interesse de pesquisadores, editoras, produtores de cinema e do público leitor. Hoje é possível encontrar um grande número de publicações de traduções e adaptações de sua vasta obra ficcional aqui no Brasil.

Um exemplo da grande popularidade de Poe no sistema literário brasileiro é a tese de doutorado de Alves (2014), intitulada Os paratextos das antologias brasileiras de contos de Edgar Allan Poe no século XXI, e que traz no primeiro capítulo um levantamento de todas as traduções de contos do escritor publicadas no Brasil até o ano de 2013, o que chega ao montante de 397 traduções e que vem reiterar a grande receptividade do contista no nosso país.

Assim, em face do que foi exposto sobre a recepção de Poe em diversos sistemas literários, podemos observar o quanto sua obra tem inspirado tantos renomados escritores da literatura universal e levado tantas nações a introduzirem sua obra em suas línguas de origem, o que tem atraído uma legião de leitores cada vez maior. Vemos que figuras do quilate de Baudelaire, Balmont, Cortázar, Pessoa, Machado de Assis e outros se renderam à genialidade literária de Poe, seja se inspirando no mesmo, seja traduzindo sua obra. Convém observar que a literatura poeana também foi levada a outros países (além dos acima citados), através das traduções, como República Tcheca, Croácia, Japão, China e Índia. Nota-se, portanto, a reputação e a popularidade conquistadas pelo escritor estadunidense, que teve sua obra disseminada em quase todo o mundo. 
ALVES, F. F. DE S. - Poe: uma história de traduções, inspirações e popularidade

\section{Referências bibliográficas}

Abramo, C. W. A espada no livro. Disponível em: www.scribb.com/doc/18047587/analise-corvo.

ALVES, F. F. S. Os paratextos das antologias brasileiras de contos de Edgar Allan Poe no século XXI. 2014. 232p. Tese (Doutorado em Estudos da Tradução) - Centro de Comunicação e Expressão, Universidade Federal de Santa Catarina, 2014.

Araúso, R. Edgar Allan Poe: um homem em sua sombra. Cotia/SP: Ateliê Editorial, 2002.

Bacigalupo, M. Poe in Italy. In: VINeS, L. D. Poe Abroad. lowa: University of lowa Press, 1999.

BAUdelaiRe, C. $O$ homem $e$ a obra. Disponível em: www.allanpoe4.blogspot.com.br. Acesso em: 19 set. 2012.

DAGHLIAN, C. Poe in Brazil. In: VINES, L. D. Poe Abroad. lowa: University of lowa Press, 1999.

D'AMELIO, N. Edgar Allan Poe's Extraordinary Translations: A Survey of Nineteenth- and Early Twentieth-Century French and Russian Versions. In: Anglo Saxonica. Ser. III, n. 1, 2010, ISSN: 0873-0628. Disponível em: http://dspace.uevora.pt/rdpc/bitstream/10174/3955/1/as28-iii-web-jpgs. pdf

FIgUeiRedo, V. C. Fortuna literária de Edgar Allan Poe traduzido em Portugal. Cadernos de Tradução, v. 2, n. XXIV, Florianópolis (UFSC), 2009, pp. 65-94. Disponível em: www. periodicos.ufsc.br/index.php/tradução.

ForCLAZ, R. Poe in Germany and Austria. In: VINES, L. D. Poe Abroad. lowa: University of lowa Press, 1999.

GONÇALVES, F. B. Tradução, interpretação e recepção literária: manifestações de Edgar Allan Poe no Brasil. Dissertação de Mestrado - Universidade Federal do Rio Grande do Sul, 2006.

LENTZ, G. Charles Baudelaire: esboços para uma poética da tradução. Scientia Traductionis, $\mathrm{n}^{\circ}$ 6, Florianópolis (UFSC), pp. 1-7, 2008. Disponível em: www. periodicos.ufsc.br/index.php/scientia.

Mendes, O. Influência de Poe no estrangeiro. In: PoE, E. A. Ficção completa, Poesia e Ensaios. Org. e trad. Oscar Mendes \& Milton Amado. Rio de Janeiro: Nova Aguilar, 2001: 53-56. 
ALVES, F. F. DE S. - Poe: uma história de traduções, inspirações e popularidade

MoReIRA, M. E. R. Leituras de Poe: sua obra na voz de escritores. In: Congresso Internacional Para Sempre Poe. Anais... Belo Horizonte: UFMG, 2009: 216-221.

RónAl, P. Escola de tradutores. $5^{a}$ ed. rev. Ampl. Rio de Janeiro: Nova Fronteira, INL, 1987.

Rosselet, J. Poe in France. In: Poe in Foreign Lands and Tongues: a symposium at the nineteenth annual commemoration of the Edgar Allan Poe Society of Baltimore in Westminster Church. Baltimore: The Johns Hopkins Press, 1941: 5-9. Disponível em: www.eapoe.org.

SALINAS, P. Poe in Spain and Spanish America. In: Poe in Foreign Lands and Tongues: a symposium at the nineteenth annual commemoration of the Edgar Allan Poe Society of Baltimore in Westminster Church. Baltimore: The Johns Hopkins Press, 1941: 23-28. Disponível em: www.eapoe.org.

SantaelLa, L. Estudo crítico: Edgar Allan Poe ( 0 que em mim sonhou o que está pensando). In: Os melhores contos de Edgar Allan Poe. Trad. José Paulo Paes. São Paulo: Círculo do Livro, 1987: 139-189.

TODORov, T. Os gêneros do discurso. $1^{\text {a }}$ ed. Tradução de Elisa Angotti Kossowitch. São Paulo: Martins Fontes, 1980. 